\title{
Article
}

\section{Short-Facelift Approach in Temporal Artery Biopsy: Is It Safe?}

\author{
Mario Faenza ${ }^{1, *}$, Giuseppina Piccolo ${ }^{1}$, Mariano Funaro ${ }^{1}$, Roberto Grella ${ }^{1}$ (D) , Ilenia Pantano ${ }^{2}$ \\ and Francesco Ciccia ${ }^{2}$
}

1 Plastic Surgery Unit, Multidisciplinary Department of Medical Surgical and Dental Sciences, University of Campania 'Luigi Vanvitelli', 80138 Naples, Italy; giuseppina.piccolo@unicampania.it (G.P.); mariano.funaro@gmail.com (M.F.); info@robertogrella.it (R.G.)

2 Division of Rheumatology, Department of Precision Medicine, University of Campania 'Luigi Vanvitelli', 80138 Naples, Italy; ilenia.pantano@libero.it (I.P.); francesco.ciccia@unicampania.it (F.C.)

* Correspondence: mario.faenza@unicampania.it

Citation: Faenza, M.; Piccolo, G.; Funaro, M.; Grella, R.; Pantano, I.; Ciccia, F. Short-Facelift Approach in Temporal Artery Biopsy: Is It Safe? Appl. Sci. 2021, 11, 10739. https:// doi.org/10.3390/app112210739

\section{Academic Editors:}

Salvatore D'Amato, Mario Santagata and Raffaele Rauso

Received: 6 October 2021

Accepted: 10 November 2021

Published: 14 November 2021

Publisher's Note: MDPI stays neutral with regard to jurisdictional claims in published maps and institutional affiliations.

Copyright: (C) 2021 by the authors. Licensee MDPI, Basel, Switzerland. This article is an open access article distributed under the terms and conditions of the Creative Commons Attribution (CC BY) license (https:// creativecommons.org/licenses/by/ $4.0 /)$.

\begin{abstract}
Giant cell arteritis (GCA) is a quite common panarteritis of the elderly that affects mediumand large-size arteries. Despite the increasing role of imaging with advancing technology, the gold standard for the diagnosis of GCA is still the temporal artery biopsy. A described complication of superficial temporal artery biopsy (STAB), for which incidence is not clear, is the accidental damage of the frontal branch of the facial nerve. In this paper, we described the short-scar facelift surgical approach for STAB on 23 consecutive patients who underwent unilateral superficial temporal artery biopsy for GCA suspicion. We collected data in terms of postoperative complications, biopsy specimen length, biopsy result and cosmetic appearance of the scar. In our experience, this surgical approach combines the advantage of avoiding incisions within the dangerous anatomical area, minimizing the risk of facial nerve damage, with an acceptable complication rate and a good final aesthetic result which avoids visible scarring.
\end{abstract}

Keywords: minimally invasive procedure; new tools in diagnosis; giant cell arteritis; temporal artery biopsy

\section{Introduction}

Giant cell arteritis (GCA) is a quite common panarteritis of the elderly that affects medium- and large-size arteries.

This type of vasculitis commonly involves the superficial temporal branches of the external carotid artery and the ophthalmic branch of the internal carotid artery.

GCA has its peak of incidence between 70 and 80 years and it is more common in females than in males, especially among the Northern European population [1].

There is still an open debate regarding pathogenesis of this clinical condition; regardless, all theories are in agreement in affirming that the immunopathology of GCA is due to an active immune response towards the vessel wall. The immune response involves T-cells and macrophages that infiltrate the boundary of the media and intima, leading to a granulomatous inflammation that promotes the formation of giant cells, and this is the reason why this vasculitis is named giant cell arteritis [2].

The classic symptoms are related to the local vascular damage resulting in vessel wall hyperplasia and arterial occlusion, and consist of headaches, jaw claudication, and visual impairments [3].

Other clinical manifestations of GCA are related to a systemic inflammatory status and consist of fever, malaise, polymyalgia rheumatica, anorexia, and weight loss.

The major clinical complication of GCA is blindness, which can only be prevented by an early detection and treatment [4].

Concerning physical examination, upon palpation, the superficial temporal artery can be increased in thickness, and become tender, erythematous, and with a decreased pulse. 
Nevertheless, $50 \%$ of patients affected by GCA present normal physical findings on palpation of the superficial temporal artery.

The diagnostic algorithm also includes blood tests in order to determine erythrocyte sedimentation rate (ESR) and C-reactive protein (CRP), which are non-specific markers of inflammation disease.

Despite the increasing role of imaging with advancing technology, the gold standard for the diagnosis of GCA is still the temporal artery biopsy [5].

The length of biopsy specimens varies from $2 \mathrm{~cm}$ to $3-5 \mathrm{~cm}$ in patients with and without signs of temporal arteritis, respectively [6].

Skip lesions are frequent in GCA, thus an adequate specimen is crucial in order to prevent missing the affected portion of the vessel and to avoid a false negative result.

A described complication of superficial temporal artery biopsy (STAB), for which incidence is not clear, is the accidental damage of the frontal branch of the facial nerve [7].

In every case of facial nerve impairment after STAB described in the literature, incisions were placed within the known course of the frontal branch of the facial nerve.

In this paper, we describe the short-scar facelift surgical approach for STAB and a case series study.

\section{Materials}

We retrospectively reviewed 23 consecutive patients, 19 females (82.6\%) and 4 males $(17.4 \%)$, who underwent unilateral superficial temporal artery biopsy for GCA suspicion.

The patients were aged between 72 and 84 years of age (mean 77.39), and 14 out of 23 $(60.8 \%)$ presented clinical signs on palpation of the superficial temporal artery.

We collected data in terms of postoperative complications, biopsy specimen length, biopsy result, and cosmetic appearance of the scar.

Regarding the quality of the scar, we used a visual analog scale (VAS) with a score between 0 and 5 , where 0 represents the worst cosmetic appearance and 5 represents the best cosmetic appearance at six months after the surgical procedure.

\section{Methods}

The short-scar facelift incision starts from the retrotragal region and reaches the sideburn area. (Figure 1)

Local anesthesia with 1\% Mepivacaine is injected into and beneath the overlying skin.

The skin incision is performed with a $\mathrm{n} .15$ blade and deepened until the subdermal fat is encountered, and then the skin flap is dissected with a double prong hook retractor and Rees Scissor above the superficial muscle aponeurotic system (SMAS) for $2-3 \mathrm{~cm}$.

Once the SMAS has been exposed, this fascial plane is incised $1-2 \mathrm{~cm}$ in front of the tragus and the incision is extended superiorly for $3-5 \mathrm{~cm}$ in order to harvest a conjoined fascial flap of SMAS and pretemporal fascia.

Then, the harvested conjoined fascial flap is anteriorly dissected for $1-2 \mathrm{~cm}$ and reflected with a Weitlaner blunt self-retaining retractor.

At this point, the superficial temporal artery comes into view and can be dissected easily from the vein up to its superior bifurcation. (Figure 2) 


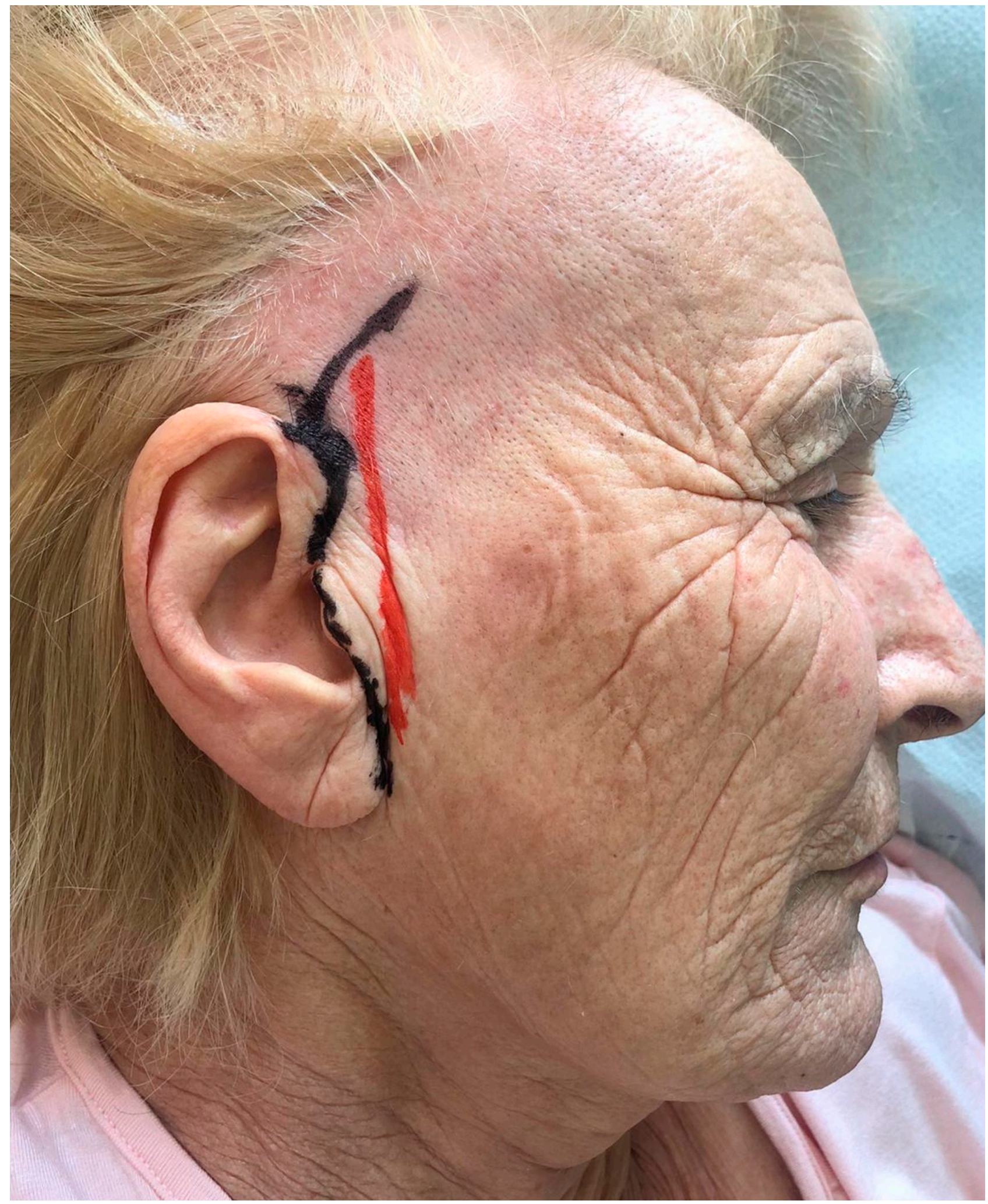

Figure 1. Preoperative markings of the short-scar facelift incision. 


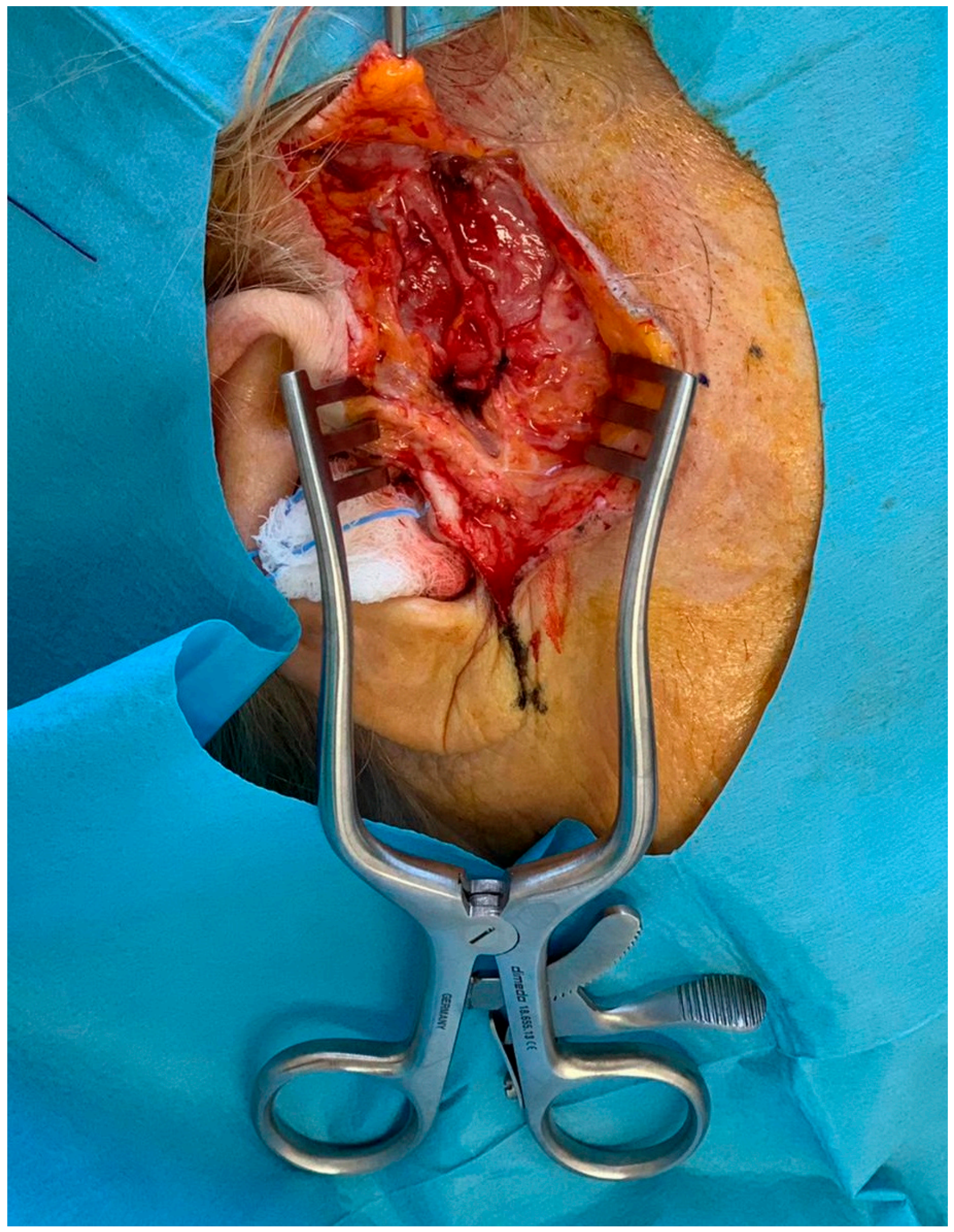

Figure 2. Intraoperative view of the dissected temporal artery.

Collateral and adjacent vessels are ligated and cut until an adequate length of the specimen is reached, then the artery can be harvested and measured with a sterile ruler. 
Accurate hemostasis is obtained with bipolar forceps and the skin closure is performed with $5 / 0$ nylon interrupted sutures.

Dressing changes occur every 2 days and stitches are removed 7-10 day postoperative. (Figure 3).
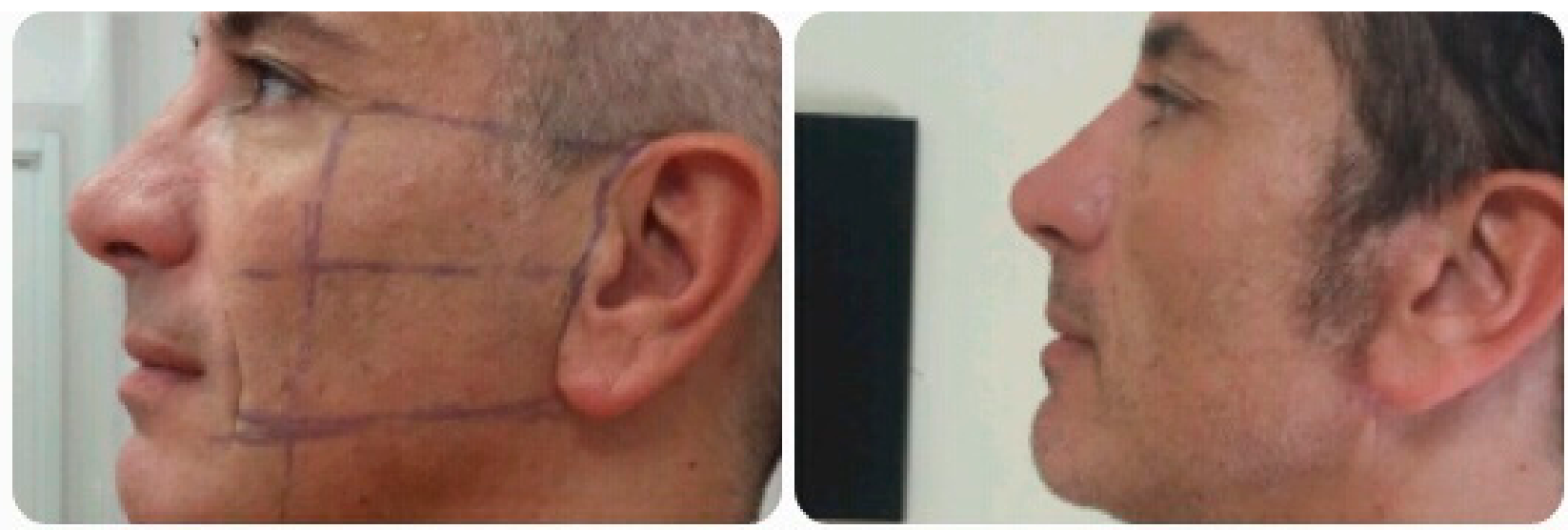

Figure 3. Preoperative and postoperative view.

\section{Results}

The mean length of the collected sample was $2.60 \mathrm{~cm}$ and 17 of the 23 biopsies $(73.91 \%)$ came back positive for GCA.

In terms of aesthetic result, the finding of an average value of 4.04 at six months postoperative with the VAS scale demonstrated a good long-term aesthetic outcome. (Table 1)

Table 1. Postoperative Results.

\begin{tabular}{ll}
\hline Parameters & Results (Mean) \\
\hline Length of specimen $(\mathrm{cm})$ & $2.60 \mathrm{~cm}$ \\
\hline Pathology Report $(\%)$ & $73.91 \%$ positive for GCA \\
\hline Scar quality (VAS) & 4.04 \\
\hline
\end{tabular}

In terms of postoperative complications, no injury to facial nerve was registered. (Table 2).

Table 2. Postoperative Complications Results.

\begin{tabular}{ll}
\hline Postoperative Complications & Results (Mean) \\
\hline Hematoma & $2(8.69 \%)$ \\
\hline Infection & $1(4.34 \%)$ \\
\hline Partial Wound Dehiscence & $2(8.69 \%)$ \\
\hline
\end{tabular}

\section{Discussion}

According to the American College of Rheumatology, the diagnosis of GCA requires at least three of the following five criteria: age $>50$ years, new-onset localized headache, temporal artery tenderness, ESR $>50 \mathrm{~mm} / \mathrm{h}$ and a positive result of temporal artery biopsy (TAB) [8].

Nevertheless, a positive temporal artery biopsy still represents the gold standard in the diagnosis of GCA.

The debate about how and when to sample the artery is still open: giant cell arteritis often causes a patchy inflammatory status leading to so-called skip lesions. Due to this 
pathological pattern, evaluation of short artery specimens may miss the affected areas, leading to false negative results $[9,10]$.

Furthermore, the temporal artery biopsy procedure is not complication free: in fact, the close proximity between artery and frontal branch of the facial nerve puts the patient at risk of facial palsy.

This complication has been reported in the literature mainly as case series articles, and most of them described biopsies taken in the frontal area.

Damage to the frontal branch of the facial nerve can cause paralysis with drooping of the eyebrow, loss of eyebrow elevation, and loss of eyelid closure with varying recovery rates [11].

In 2012, Murchinson et al. [12] published a prospective analysis of 75 temporal artery biopsies discovering that there is a $16.0 \%$ incidence of postoperative frontal branch of facial nerve damage, which fully recovers in over half of the patients. Furthermore, they found that incisions closer to the orbital rim and eyebrow were more likely to have facial nerve damage, supporting the description of an anatomical danger zone in which surgical incisions for TAB should be strongly discouraged $[7,13]$.

In order to avoid incisions in the danger zone, alternative surgical approaches for TBA have been proposed both at the scalp level $[14,15]$ and at the level of the preauricular wrinkle crease [16].

In 2019, Czyz et al. [17] conducted a retrospective study on 137 temporal artery biopsies with incisions at the level of the temporal hairline without injury to the facial nerve.

Facelift incision has been extensively described for cancer interventions such as parotidectomy and neck dissection as it results in cosmetically improved outcomes [18-20].

In this article, we have described the use of a short-facelift incision in temporal artery biopsy; this surgical approach combines the advantage of avoiding incisions within the dangerous anatomical area, minimizing the risk of facial nerve damage, with an acceptable complication rate and a good final aesthetic result that avoids visible scarring.

A possible limitation could be represented by the fact that our case series is smaller than the previous works described, but the data we have collected are encouraging.

Finally, it can be of great help for trainees to become familiar with the cosmetic facelift surgical procedure.

Author Contributions: Conceptualization: M.F. (Mario Faenza) and F.C. Methodology: G.P. Validation: I.P. Investigation: R.G. Data curation: M.F. (Mariano Funaro). Writing—original draft preparation: M.F. All authors have read and agreed to the published version of the manuscript.

Funding: This research received no external funding.

Institutional Review Board Statement: Ethical review and approval were waived for this study, due to the fact that it is not an experimental study.

Informed Consent Statement: Informed consent was obtained from all subjects.

Data Availability Statement: Plastic Surgery Unit, Multidisciplinary Department of Medical Surgical and Dental Sciences, University of Campania 'Luigi Vanvitelli', Piazza Luigi Miraglia,2, 80138, Naples, Italy phone number: 00390815664072.

Conflicts of Interest: The authors declare no conflict of interest.

\section{References}

1. Borchers, A.T.; Gershwin, M.E. Giant cell arteritis: A review of classification, pathophysiology, geoepidemiology and treatment. Autoimmun. Rev. 2012, 11, A544-A554. [CrossRef] [PubMed]

2. Salvarani, C.; Cantini, F.; Hunder, G.G. Polymyalgia rheumatica and giant-cell arteritis. Lancet 2008, 372, 234-245. [CrossRef]

3. Harder, N. Temporal arteritis: An approach to suspected vasculitides. Prim. Care 2010, 37, 757-766. [CrossRef] [PubMed]

4. Epperly, T.D.; Moore, K.E.; Harrover, J.D. Polymyalgia rheumatica and temporal arthritis. Am. Fam. Phys. 2000, 62, 789-796.

5. Meskimen, S.; Cook, T.D.; Blake, R.L., Jr. Management of giant cell arteritis and polymyalgia rheumatic. Am. Fam. Phys. 2000, 61, 2061-2068.

6. Schallhorn, J.; Haug, S.J.; Yoon, M.K.; Porco, T.; Seiff, S.R.; McCulley, T.J. A national survey of practice patterns: Temporal artery biopsy. Ophthalmology 2013, 120, 1930-1934. [CrossRef] [PubMed] 
7. Gunawardene, A.R.; Chant, H. Facial nerve injury during temporal artery biopsy. Ann. R. Coll. Surg. Engl. 2014, 96, 257-260. [CrossRef] [PubMed]

8. Hunder, G.G.; Bloch, D.A.; Michel, B.A.; Stevens, M.B.; Arend, W.P.; Calabrese, L.H.; Edworthy, S.M.; Fauci, A.S.; Leavitt, R.Y.; Lie, J.T.; et al. The American College of Rheumatology 1990 criteria for the classification of giant cell arteritis. Arthritis Rheumatol. 1990, 33, 1122-1128. [CrossRef] [PubMed]

9. Albert, D.M.; Ruchman, M.C.; Keltner, J.L. Skip areas in temporal arteritis. Arch. Ophthalmol. 1976, 94, 2072-2077. [CrossRef] [PubMed]

10. Stacy, R.C.; Rizzo, J.F.; Cestari, D.M. Subtleties in the histopathology of giant cell arteritis. Semin. Ophthalmol. 2011, 26, 342-348. [CrossRef] [PubMed]

11. Yoon, M.K.; Horton, J.C.; McCulley, T.J. Facial nerve injury: A complication of superficial temporal artery biopsy. Am. J. Ophthalmol. 2011, 152, 251-255.e1. [CrossRef] [PubMed]

12. Murchison, A.P.; Bilyk, J.R. Brow ptosis after temporal artery biopsy: Incidence and associations. Ophthalmology 2012, 119, 2637-2642. [CrossRef] [PubMed]

13. Colella, G.; Rauso, R.; Tartaro, G.; Biondi, P. Skin injury and great auricular nerve sacrifice after parotidectomy. J. Craniofac. Surg. 2009, 20, 1078-1081. [CrossRef] [PubMed]

14. Markose, G.; Graham, R.M. Gillies temporal incision: An alternate approach to superficial temporal artery biopsy. Br. J. Oral Maxillofac. Surg. 2017, 55, 719-721. [CrossRef] [PubMed]

15. Conde-Ferreirós, A.; Fraile-Alonso, M.D.C.; Román-Curto, C. “Book Flap” Approach for Temporal Artery Biopsy. Dermatol. Surg. 2020, 46, 1361-1363. [CrossRef] [PubMed]

16. Charlesworth, P. Regarding temporal artery biopsy technique. Dermatol. Surg. 2001, 27, 608. [PubMed]

17. Czyz, C.N.; Allen, J.B.; Cahill, K.V.; Nabavi, C.B.; Foster, J.A. Effects of incision location on specimen quality and complications for temporal artery biopsy. Vascular 2019, 27, 347-351. [CrossRef] [PubMed]

18. Grover, N.; D'Souza, A. Facelift approach for parotidectomy: An evolving aesthetic technique. Otolaryngol. Head Neck Surg. 2013, 148, 548-556. [CrossRef] [PubMed]

19. Melvin, T.A.; Eliades, S.J.; Ha, P.K.; Fakhry, C.; Saunders, J.M.; Califano, J.A.; Blanco, R.G. Neck dissection through a facelift incision. Laryngoscope 2012, 122, 2700-2706. [CrossRef] [PubMed]

20. Tae, K.; Ji, Y.B.; Song, C.M.; Sung, E.S.; Chung, J.H.; Lee, S.H.; Park, H.J. Feasibility of robot-assisted modified radical neck dissection by post-auricular facelift approach. Int. J. Oral Maxillofac. Surg. 2016, 45, 1351-1357. [CrossRef] [PubMed] 